\title{
Past and Present
}

\author{
MATTHEW P. ROMANIELLO
}

Cifty years ago, in 1968, the journal Literaturnaia gazeta published a remarkable article, "Save the Men!," opening a public discussion of the demographic crisis in the Soviet Union for the first time. In this issue of Sibirica, Tricia Starks translates the article in order to highlight its importance both to the Soviet Union and also for current scholarship. It is not a coincidence that this issue also features Vera Skvirskaja's discussion of marriage practices among the Nenets community. Current habits and discussions about marriage have an established precedent in modern Russia. This is not a phenomenon produced by the changes to society in the post-Soviet era, nor is it only a reflection of greater public awareness of the state of health across Russia. This is a historically constructed process with deep roots in the past.

As Sibirica moves forward, I hope to highlight more connections between past and present. As an interdisciplinary journal regularly featuring the work of historians and social scientists, Sibirica is positioned to feature the works of scholars that bridge the disciplinary "divide" and publish research that addresses fundamental issues that influence all of our work. I hope to encourage our colleagues to think topically and work with an awareness of how other disciplines can contribute to our collective project of better understanding "Siberia" (writ large) as a unique space with a long history and an important future.

This issue features work from scholars from a breadth of disciplines: history, anthropology, linguistics, and environmental studies, to name a few. It begins with a look at the contribution of Finnish ships and sailors to the Russian American Company's efforts in the North Pacific by the eminent historian Andrei V. Grinëv. Seija A. Niemi provides an in-depth look at the career of A. E. Nordenskiöld in the late nineteenth century. While an event of the last century, Nordenskiöld's pursuit of the commerce through the northern passage has modern resonance, both in terms of its striking familiarity with current debates over global trade and its environmental damage in the region. Finally, Petia Mankova challenges the "sentimental pessimism" that has been prominently featured in recent media portrayals of the Arctic north 
with the lived experiences of the village of Krasnoshchel'e. Misunderstanding Siberia is hardly a new phenomenon of the twenty-first century, and the analysis offered by Mankova will strike scholars of the previous centuries as more familiar than different.

The strength of this journal is to publish work that appeals to a broad audience from different disciplines sharing a common project. I look forward to seeing new submissions that address this challenge in new and unique ways highlight unfamiliar peoples and places, and, increasingly, focus on problems facing Eurasia. As a historian, I hope that scholars will present more research that considers how the past informs the present, not limiting ourselves just to the recent decades but working in a wider view. After all, even the public conversation about the demographic crisis in 1968 was not new-debates about Russia's population decline began at the start of the eighteenth century, if not earlier. No one scholar can address the entire span, or easily reach conclusions on how the past influences the present, but Sibirica can act as an intermediary bringing scholars into conversation that ultimately enriches all of our work. 